\title{
Integrated Structural and Environmental Form-Finding: A Teaching Experiment
}

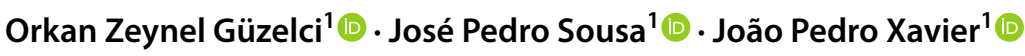

Accepted: 9 September 2021 / Published online: 25 September 2021

(c) Kim Williams Books, Turin 2021

\begin{abstract}
This paper presents a teaching experiment in which 3D digital computational models are explored as the representational base to integrate formal, structural, and environmental performance criteria in design. By describing the academic experience, the paper reflects on its methodologies and results, as well as on the relation between human and computer factors in the design process. This assessment is important to make the students aware of the increasingly intelligent design systems offered by digital technologies to support architectural design, as well as of their relationship with precedent digital and analog representational mediums.
\end{abstract}

Keywords Architectural education · Generative models · Form-finding · Environmental analysis $\cdot$ Funicular forms

\section{Introduction}

By enabling integrated design, analysis, and fabrication processes, digital technologies have created new conditions for the development of architectural projects and reconfiguring the human-computer relationship (Shea et al. 2005; Oxman 2008). Form-finding is one traditional analog processes that has opened up new possibilities in the digital realm. By connecting design generation with performative simulation, computers have made the form-finding exploration of geometric and material solutions possible in ways that would have been difficult before. As a result, the mathematical structure and logic implied in form-finding approaches have benefited from computation, sparking renewed interest in

Orkan Zeynel Güzelci

oguzelci@arq.up.pt

José Pedro Sousa

jsousa@arq.up.pt

João Pedro Xavier

jxavier@arq.up.pt

1 Faculty of Architecture + DFL/CEAU, University of Porto, Porto, Portugal

Birkhäuser 
architecture in recent years. In this context, the present paper seeks to describe and analyze a teaching experience in which students were introduced to computational form-finding processes as one of the first computing experiences of their curriculum, as computers are not normally used in the design studios at the Faculty of Architecture of the University of Porto (FAUP) during the first two years of the Integrated Master in Architecture program (MIArq).

In describing the exploration of a computational form-finding process, this paper examines the role of the designer (human) and of the digital technology (computer) in such a design process. To investigate the roles of these actors, the experienced form-finding process in the teaching experiment was segmented into stages. The authors used qualitative methods to critically evaluate the actor's intervention levels at each stage using a two-point scale (low-high).

This paper is structured in five sections. After this introduction, Sect. 2 presents the theoretical background, which is followed by an explanation of the general framework of the teaching experience in Sect. 3. Then, Sect. 4 presents the students' work by detailing the development of the works, and reflections. Based on this work, Sect. 5 discusses the relationship between human and computer factors, the methodological relation between design conception and analysis tasks, and the pedagogic results of such experience.

\section{Form-Finding and Pedagogical Frameworks}

In this section, the background to form-finding is explained with the intention of supporting the development of the student assignment. In addition, the pedagogic models and approaches are examined to set up the teaching method.

The teaching experiment presented in this study addresses and combines two themes in its overall learning objective: form-finding as a modeling strategy, and performative analysis as a design evaluation concern. The form-finding concept can be traced back to the seventeenth century, when Robert Hooke investigated the mathematical properties of the catenary. In the late nineteenth and early twentieth centuries, the catenary curve, as an example of two-dimensional geometry, became an important form-finding tool, allowing the simultaneous design and calculation of complex vault-like forms (Kilian 2004; Rippmann et al. 2012). In this manner, Antoni Gaudi used hanging chain models to generate unique design solutions (Huerta 2003). Similarly, Heinz Isler conducted several experiments testing the adequacy of physical models for form-finding (Chilton and Isler 2000). The results of Isler's experiments with soap film models showed that forms were not drawn, but emerged from those material experiments. In addition, Frei Otto developed physical experiments with materials to find and calculate optimal structural forms (Meissner and Möller 2015). In terms of computational form-finding that enables real-time exploration, a digital hanging chain modeler (Kilian 2004), RhinoVAULT (Rippmann et al. 2012), and Kangaroo plug-ins (Piker 2013) have been introduced.

By the end of the twentieth century, in addition to generative approaches for form-finding, digital tools began to support the evaluation of design performance (e.g. structural, solar, wind, thermal). Oxman (2008) conceptualized performative 
design as a holistic design approach consisting of a geometric model, evaluation processes, and a system to interact with digital models. Ekici et al. (2019) expanded form generation and performance evaluation towards optimization, introducing performative computational architecture (PCA) as a framework. Considering the many factors influencing the environmental performance of a design solution (Peters and Peters 2018), the present overview focuses on solar analysis, as it was the design performance explored in the teaching experiment presented here.

The traditional tools used for solar analysis are solar charts, which allow determining the direction and inclination of the sun on a specific place in the globe and on a specific hour and day of the year. This information has allowed architects to calculate the shadows produced on and by a design solution through a series of manual geometric procedures. Parallel with this projective approach, up until the 2000s architects used physical models and (mechanical) mock-ups that simulate the sun to evaluate the solar performance of their designs (Bodart et al. 2007; Horvat and Wall 2012). Due to the increase of computer power and the rise of building performance topics in the field of architecture, in the last two decades several computational environmental performance analysis tools and models have been developed. There are contributions with a specific focus on optimizing natural lighting (Caldas 2008) and optimizing multiple environmental performances such as solar gain control, thermal comfort, and daylighting (Turrin et al. 2011), to name a few. Another environmental analysis plug-in, Ladybug developed by Roudsari et al. (2013), has been integrated with Galapagos and Octopus optimization tools in Grasshopper to explore issues related to solar analysis (Kim et al. 2019). Briefly, form-finding and solar analysis tools have evolved from analog to digital to generative. This evolution has facilitated the back-and-forth interaction between the designer and the form alternatives, making it possible to produce and evaluate a variety of alternatives in a short time.

There is also a growing interest in the pedagogy of computational design and the construction of relevant skills. One of the most widely adopted theoretical origins in this context is "learning by doing," which can be traced back to the constructivist learning theory of Piaget (1972) and Papert (1993), as well as the reflection and experimentation conception of Dewey (1933). Distinct from the traditional assumption that "knowledge is information," learning by doing leads to a consideration that "knowledge is experience." Therefore, it allows an emphasis on students who actively learn and are not just taught. In that sense, project-based pedagogical approaches can be considered as a foundation for learning by doing, while providing both formal and informal learning possibilities together, individual and group work opportunities, and a subjective base for problem-solving research (Mills and Treagust 2003).

In the context of computational form-finding, project-based pedagogy has been explored by many scholars in undergraduate and graduate-level courses and intensive student workshops. The themes of those teaching experiments vary from structural surfaces and their optimization (Coelho et al. 2014; Adriaenssens et al. 2015; Naboni 2016) to exploration of material-based form alternatives (Symeonidou 2016; Borgart et al. 2018; Henriques and Franco 2020) and designing through structural and environmental performances (Holzer 2016; Yazici 2021). As many 
of these pedagogies appear to focus on a singular performance, this paper focuses on the exploration of integrated methods covering structural and environmental criteria in the context of computational form-finding. While in studies using projectbased pedagogy in computational form-finding, some researchers shared their own observations verbally (Holzer 2016; Symeonidou 2016), other researchers tested the success of the applied methodology through evaluation or opinion surveys (Coelho et al. 2014; Adriaenssens et al. 2015).

\section{The Teaching Experiment}

\section{The Class: Constructive Geometry 2}

This study presents a teaching experiment that was conducted by the authors in the Constructive Geometry 2 (CG2) class, a 3rd-year elective course of the Integrated Master in Architecture program (MIArq) at FAUP during the second semester of the 2019/2020 academic year. At FAUP, students of the MIArq still rely on hand drawing in the design studio during the first two years of the curriculum. Although they have their first contact with computers in the 1st year course on Geometry and Architecture, the comprehensive introduction to its use only occurs in the 3rd year, if they choose the two optional and semester-long courses of Constructive Geometry 1 (CG1) and Constructive Geometry 2 (CG2).

Practically all the students of the CG2 course arrive with the skills gained from the previous CG1 course. Starting with introducing the basics of CAD software Rhinoceros for modeling, CG1 introduces them next to parametric modeling processes using the Grasshopper visual programming environment and digital fabrication concepts and processes. The CG2 course further continues with digital exploration by exploring more advanced geometric challenges related to design and construction in architecture. Students of the course are expected to combine new skills with the ones previously learned. Since neither course is a design studio, the teaching of digital technologies unfolds through the exploration of geometric problems that call for thinking and making processes with the help of the computer. As a result, the two courses present a set of progressive sequences of assignments that evolve from understanding and using the computer as a modeling tool towards its use a generative one.

\section{The Assignment: Funicular Form}

In the second semester of the 2019/2020 academic year, the CG2 course was comprised of 10-15 students meeting for 13 weeks with two hours of class per week. The usual and planned teaching methodology of the CG2 course includes, but is not limited to, theoretical lectures, tutorials to introduce the use of digital processes, autonomous work, group work, discussions, fabrication of design solutions, critiques by tutors, and a final review with external guests. 
At the beginning of the second semester in February 2020, the CG2 course presented an assignment aimed at developing research-by-design work in groups of two or three students with the goal of exploring digital form-finding processes followed by the physical production of models. However, due to the unexpected COVID-19 pandemic, this later physical dimension had to be canceled. Without being able to stay in the school and use the fabrication equipment, the whole experience had to become fully digital. However, this problem opened a new pedagogic opportunity by replacing the fabrication part of the assignment with the introduction of other digital tools regarding the modeling and performative analysis processes.

The aim of the updated assignment, named "funicular form," was to encourage students to experience an integrated structural and environmental form-finding process that could generate performative design solutions. Additionally, students were asked to develop site-specific design solutions in the digital environment in a remotely conducted course. The updated structure of the CG2 course is given in Table 1.

\section{The Students' Work}

\section{Development}

The funicular form assignment began with a workshop to introduce form-finding through the design of catenary curves. From the beginning, the catenary curve had emerged as an effective concept to provide the background for the assignment. Due to its properties, it has been a driving force of many key buildings in architectural history. Thus, the first week introduced students to architectural examples such as the dome of the St. Pietro Cathedral in Rome or Antoni Gaudi's hanging chain. Then in the second week, a tutorial taught the students about the design of such curves with the help of the computer. Using the Kangaroo plugin for Grasshopper, the geometry of a catenary can be calculated according to loads, weights, and physical properties. To gain expertise, the students were asked to create compositions of catenary curves placed on a square base and to present them in an isometric view at the end of fourth week.

Following the workshop, the funicular form assignment was planned for eight weeks. Funicular forms extend the structural and geometric properties of the catenary into the realm of structural shapes. To provide some context, the student groups were challenged to design a building intervention in the exterior space of the faculty by exploring the generation of funicular forms with the help of the computer. In addition to dealing with structural issues inherent to those particular geometries, they were also asked to refine the design solutions by evaluating them according to single or multiple performative criteria. To accomplish this, the groups had to acquire new digital skills by crafting a series of parametric design and analysis procedures on the computer.

The work unfolded in the following way. In the beginning, each group selected a specific site in the faculty grounds. While working on a familiar and 


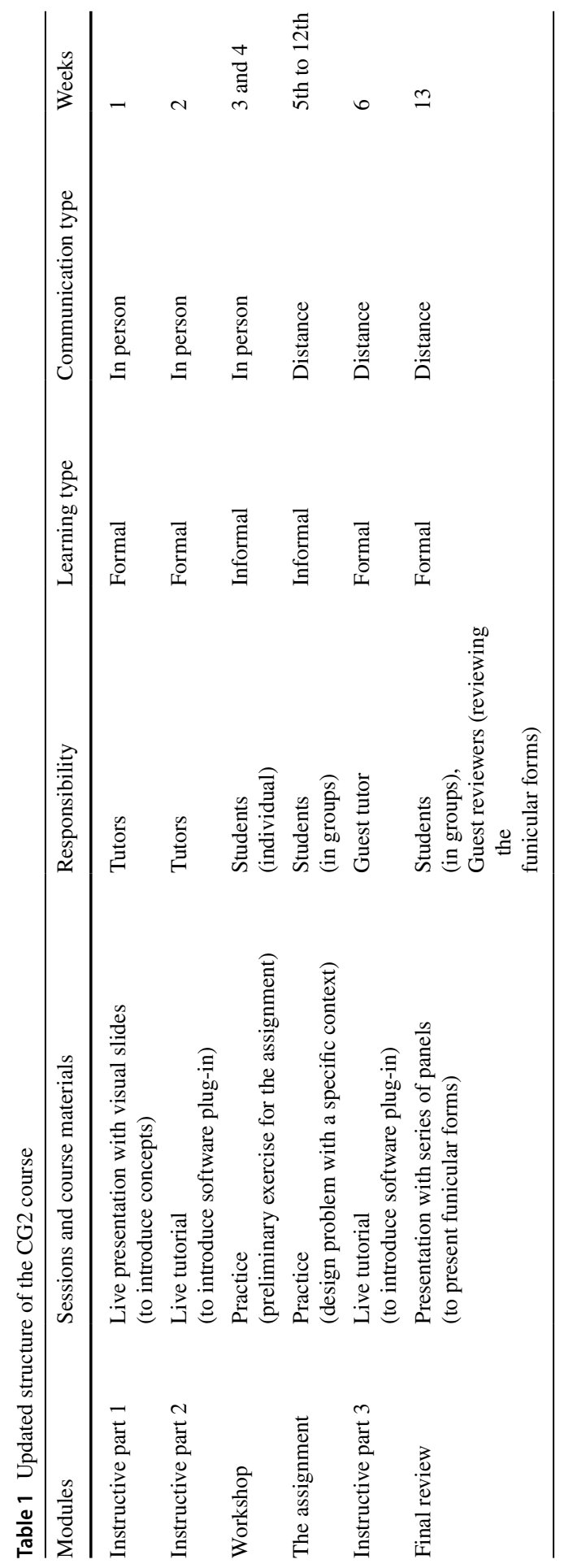




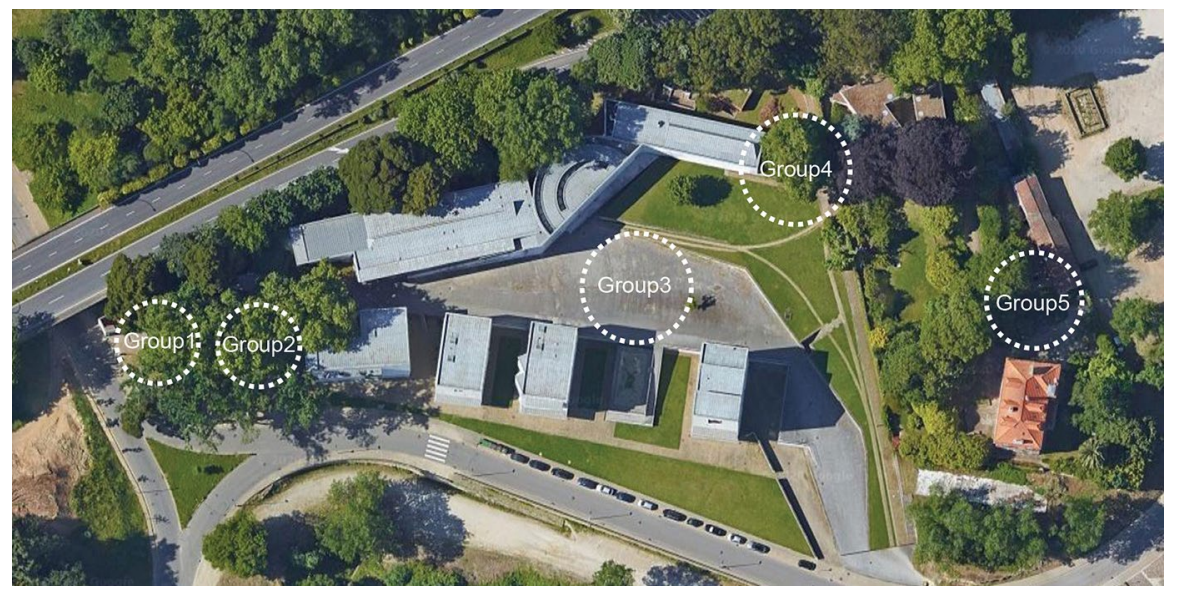

Fig. 1 Selected sites by five student groups
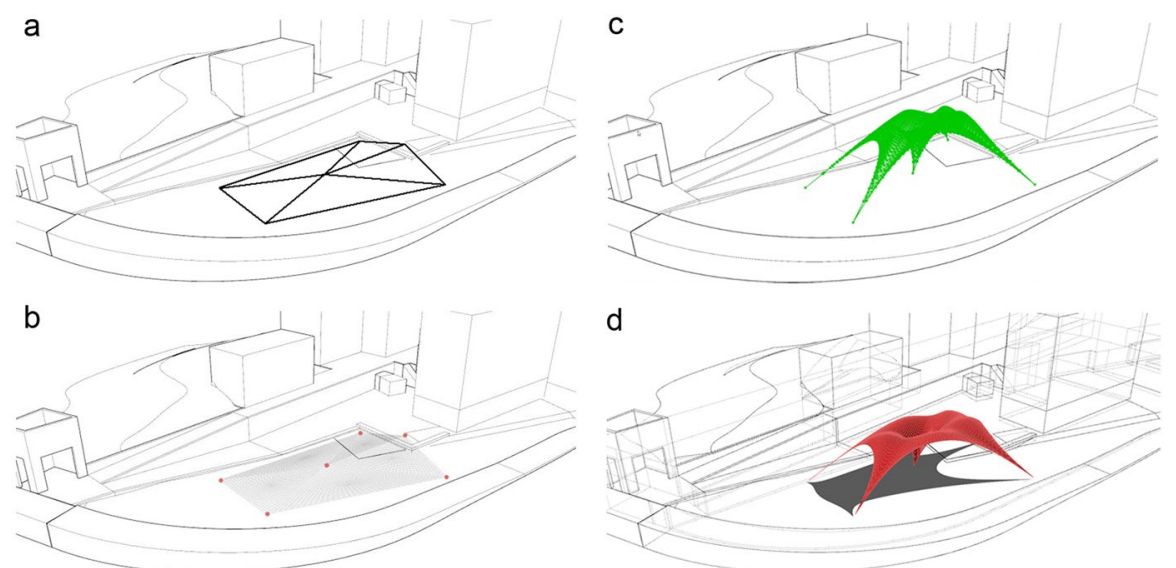

Fig. 2 Step by step generation process of a funicular form (Group 2 Nuno Gameiro and Nuno Xavier)

experienced place, the students started to consider context-related issues, such as scale, surrounding buildings, built elements (e.g. stair, ramp), landscape, axis, or viewpoints (Fig. 1) to trigger some design ideas.

Although sketching was a natural process for thinking and proposing initial design principles, from the beginning the groups began to experiment with ideas in the computer. After modeling the site in Rhinoceros, the groups immediately grasped the flexibility and agility of Kangaroo in exploring form-finding processes. The design methodology began with defining and placing a surface on the ground corresponding to the location of the funicular form (Fig. 2a). This base geometry was then transformed into an optimized mesh using Weaverbird. By setting specific anchor points and defining the loads and the material properties of this mesh, the 
computer automatically generated a funicular form (Figs. 2b, c, d; 3). By observing and discussing the results in groups, the students could revise the design parameters to generate a new, more preferable solution.

In Week 6, a guest tutor gave a tutorial on environmental analysis using the Ladybug plugin for Grasshopper. By acknowledging the ability to accommodate design changes in Kangaroo, the groups were challenged to review and adjust their designs according to daylight and shading analysis, following precise environmental data from the location. For instance, Fig. 4a visualizes the average daily sunlight in hours for February, May, and September for the site, while Fig. 4b shows the results of the sunlight analysis for three-hour intervals on the 21st of March. Besides featuring compressive structural behavior, the design solutions began also featuring intended environmental performances.

During this period of design refinement, the students were also briefed on more advanced ways to combine form and performance through the use of genetic
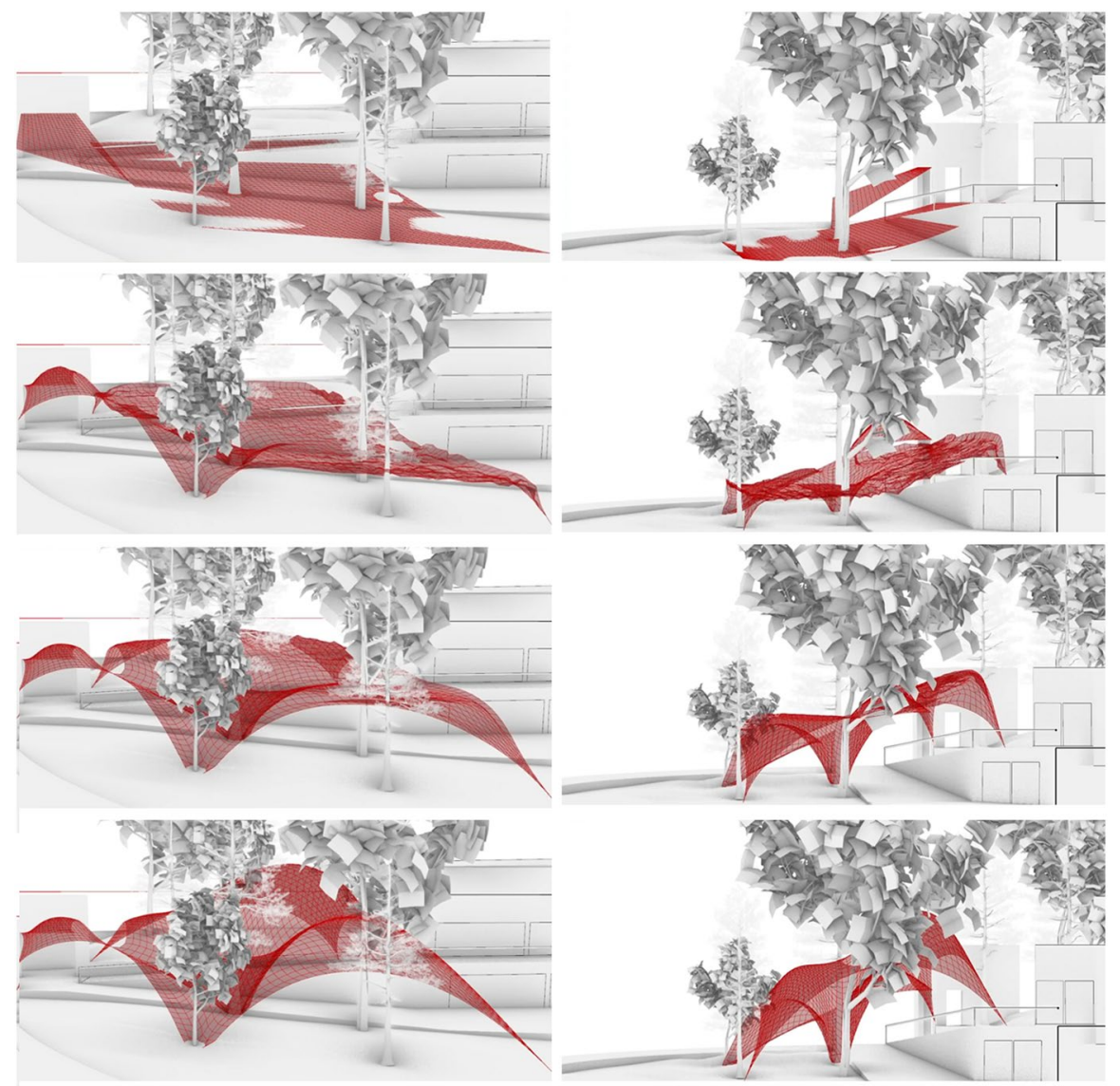

Fig. 3 Sequential generation process of a funicular form (Group 1 Tiago Rosa and Vasco Calheiros) 

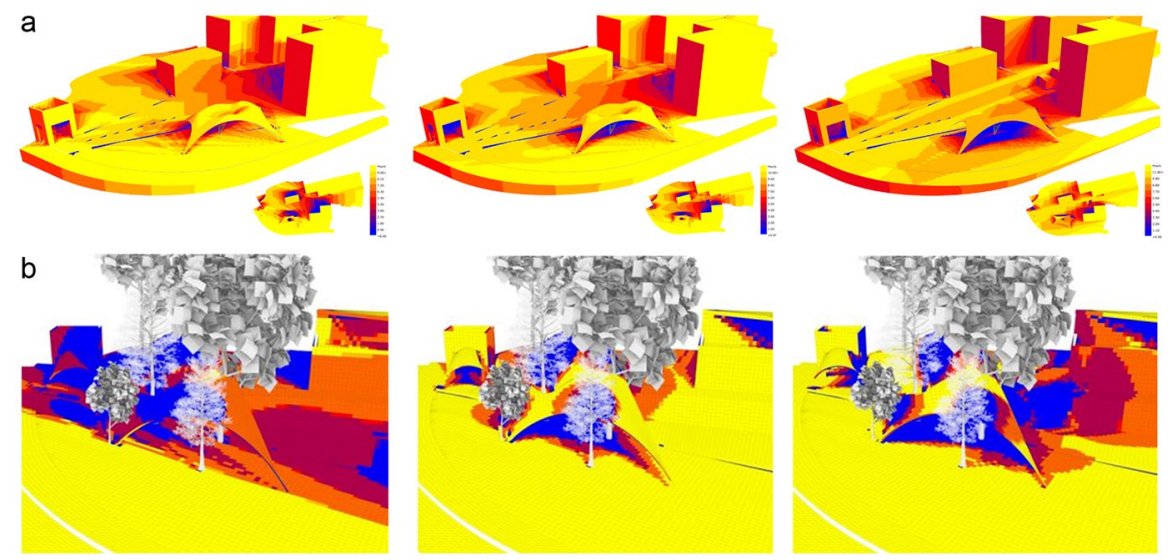

Fig. 4 Solar analysis of funicular forms a Group 2 (Nuno Xavier and Nuno Gameiro), b Group 1 (Tiago Rosa and Vasco Calheiros)

algorithms with Galapagos. When the form-finding process ended, the selected final solution was thickened using Weaverbird. In addition, the funicular form with a given thickness was exported in STL format for 3D printing. The steps of the funicular form assignment are explained and illustrated in Fig. 5.

The student groups had to document their work in a series of panels and present it on a final review in the presence of guest critics from distinguished offices in

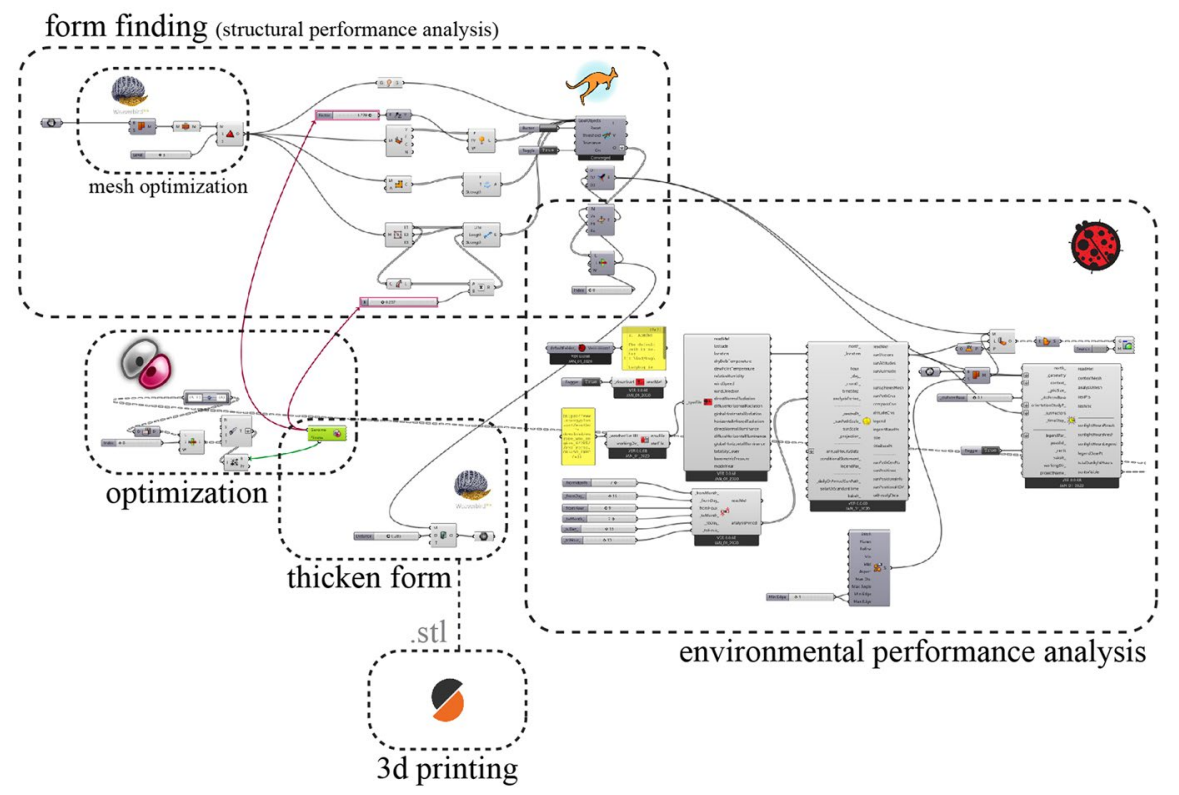

Fig. 5 Workflow of the assignment 
the field (i.e. Bjarke Ingels Group, DARK Arkitekter, and Zaha Hadid Architects). The use of animations and sequences of images and diagrams served to show the generative and active role of the computer in the process. A photomontage was also employed to give a better sense of the intervention (Fig. 6).

\section{Reflection}

During the semester, all students acquired new digital computational skills and learned about the use of strategic combinations to drive the design process. Requiring the use of different plugins, students investigated how the integration of learned skills could be used for the generation and performative evaluation of design solutions. Exploring the associative and parametric nature of computation, the design became iterative and the students could still change the foundations of their solutions near the end of the work. Technology thus introduced flexibility in the design process (Fig. 7).

Regarding the subject of the assignment, when compared to traditional methods, the challenge of designing funicular forms clearly benefited from the use of the computer. Defining the conditions and generating the resulting form occurred almost instantly and, moreover, with the necessary precision to ensure its structural integrity. Similarly, the simulation of solar or shading analysis was also a rapid process. Unlike in hand drawing processes, in a matter of minutes the environmental performance of the model could be tested at different hours, on different days, and at different times of the year. Under these conditions, the solar chart is not a graphic representation but a model. Both design and environment are models and, in this
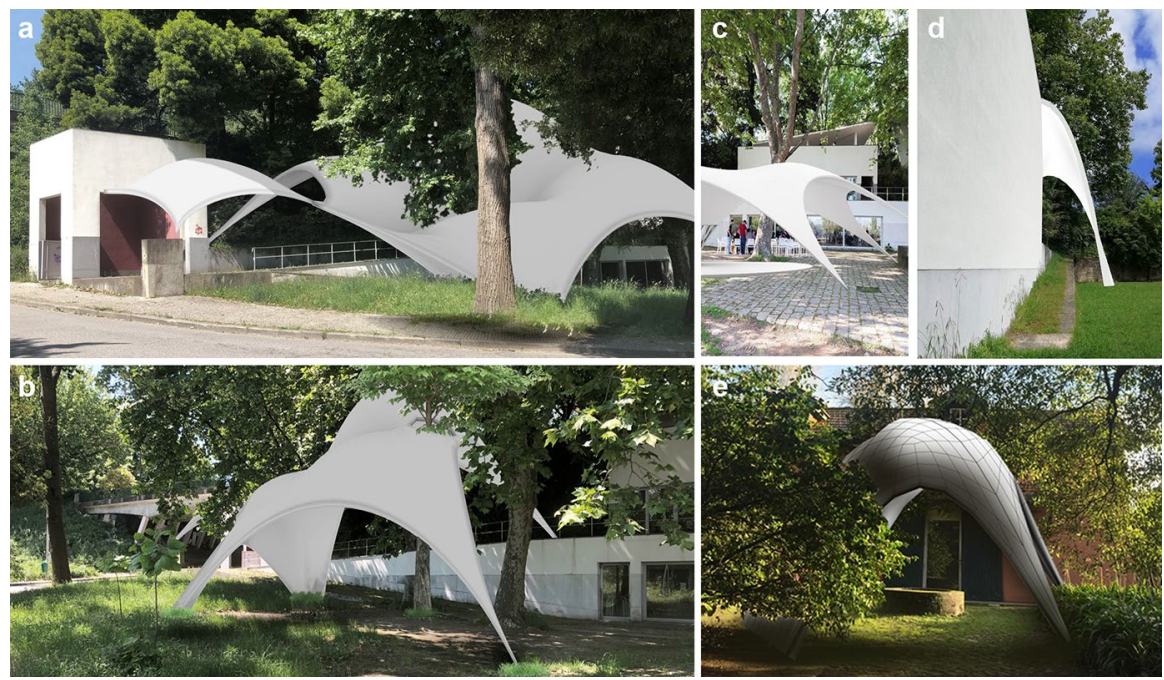

Fig. 6 Implementation of the final solutions on the site a, b Group 1 (Tiago Rosa and Vasco Calheiros), c Group 2 (Nuno Xavier and Nuno Gameiro), d Group 4 (Ana Rita Couto, Joana Ferreria, and Ricardo Faria), e Group 5 (Clara Lopes and Francisco Henriques) 
a

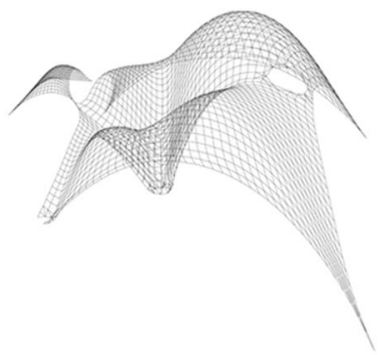

C

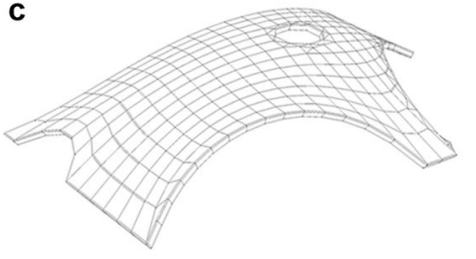

\section{b}

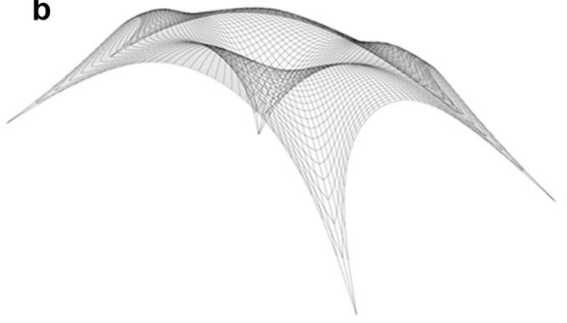

d

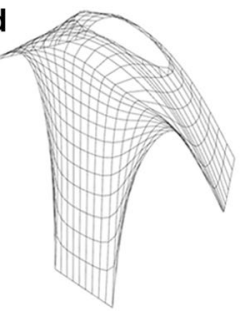

e

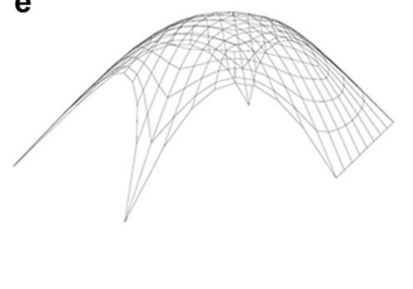

Fig. 7 Mesh representations of the generated funicular forms a Group 1 (Tiago Rosa and Vasco Calheiros), b Group 2 (Nuno Xavier and Nuno Gameiro) c Group 3 (Riccardo Martino and Henrique Martinho), d Group 4 (Ana Rita Couto, Joana Ferreria, and Ricardo Faria), e Group 5 (Clara Lopes and Francisco Henriques)

context, linked to each other. This condition was evident to the students since they had prior experience with applying solar geometry in perspective hand drawings in the first year of their studies.

During the semester, the students experienced the relationship between mathematics and architecture not directly through equations and functions, but through the features of architectural form, such as the number of points (anchors) touching to the ground, the curvature of the form, and number/resolution of the mesh parts. Apart from gaining insights into geometry, the students also practiced structures, mapping, and relating data through the advanced computation tools. Besides the critique of each group's work, the students could engage in a final conversation with the guest critics on the relevance and application of such digital technologies and processes in architectural practice. Among other inputs, the comments from guest reviewers who are in relevant fields and apply such digital tools and processes in their practices, pointed to different issues such as process, performance, function, and construction. Regarding the experienced design process and outcomes, guest reviewers stated that:

- the integration of generated forms into a site makes them unique

- some projects can be only designed with those specific tools

- digital tools can play a major role to test conceptual ideas, while bridging intuition and validation.

- a design approach enabling different processes with back-and-forth steps is appreciated

- cyclic information is extracted from the process of merging different realms. 
In addition, some of the guest reviewers' comments on performance and function are as follows:

- forms are different because they perform differently

- solar studies are reflected in the shape

- the form can make an unusable space comfortable in terms of climate

- the form offers a new sitting experience

- the top of the structure can be used as an amphitheater

- the form defines a social space

Although physical production of the generated forms was not requested from the students within the scope of this assignment, comments on the realization of the forms were also made by the jury members. In particular, they mentioned points that may reveal fragility (e.g. connection between meshes, anchor points) during the construction of the form. Also, guest reviewers offered advice regarding the possible materials and materialization strategies (e.g. weaving) to be used in the construction of the funicular forms. Following the final submission, the design solutions were 3D printed by the tutors (Fig. 8).

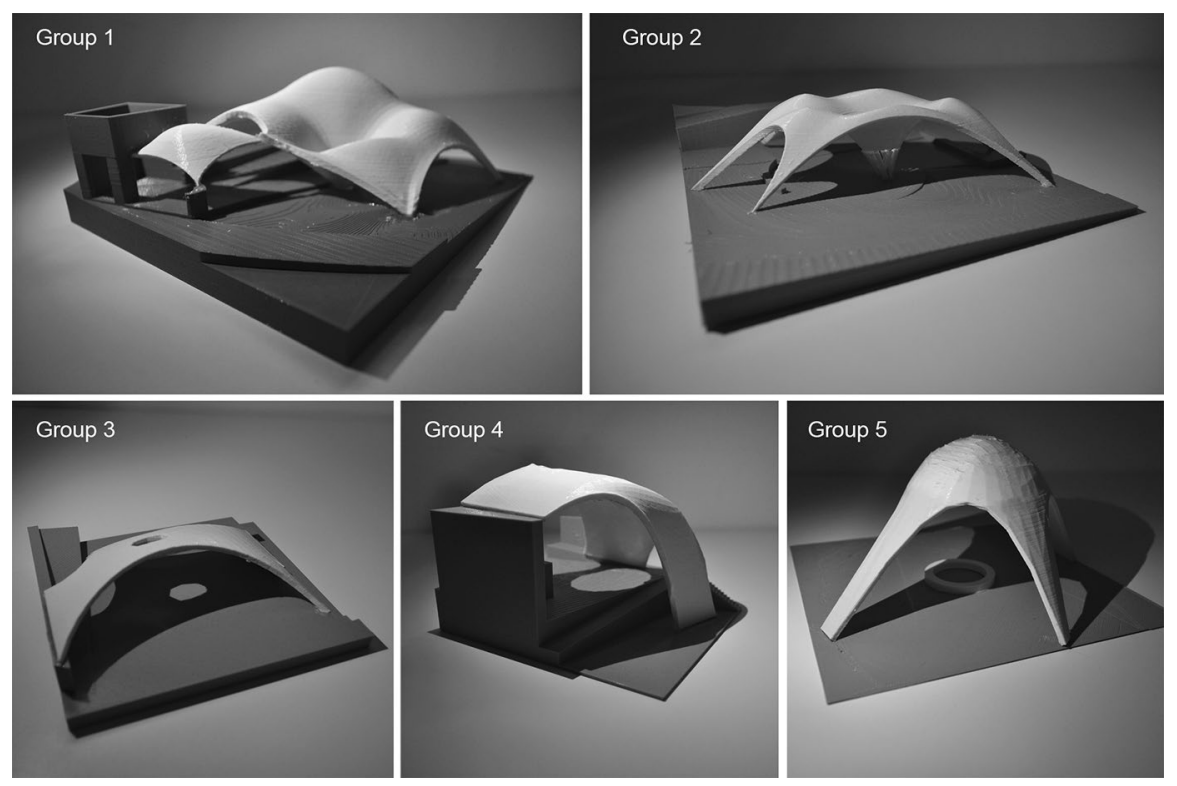

Fig. 8 3D printed models of the final solutions after the assignment 


\section{Conclusion}

This study examined the relationship between the architect (human) and digital technology (computer) in the context of computational form-finding through a teaching experiment. Instead of evaluating only the outcomes of the assignment, tutors evaluated the proposed pedagogical model based on human-computer dialogue through factors such as roles undertaken by the students and computer in the process, the time/effort spent on the operations, and the success and effectiveness of the students' partnership with the computers. In the past, the exploration of form-finding processes required devising processes that calculate the right geometry of a shape under certain anchoring, loading, and material conditions. Despite our intuition, humans cannot draw those shapes with precision unless they rely on physical or, more recently, digital computational models. Thus, this teaching experiment presented the challenge of designing a project without following conventional design approaches. In other words, students had to engage in collaboration with an artificial generative device and find their role there, both as creators and controllers in the process.

The roles of the human (architect) and digital technology (computer) in this study correspond to the intervention levels in the form-finding process, which are classified as "low" and "high." High refers to making a design decision or providing inputs that directly change the context or design solution for an architect. For the computer, a high level of intervention refers to the difficulty and the level of calculation/simulation that would be extremely difficult or impossible for the designer to perform. Most form-finding studies focusing on the evaluation of didactic teaching methodologies employ surveys or questionnaires as the main data source to measure the course's effectiveness (Coelho et al. 2014; Adriaenssens et al. 2015). The present study differs from these existing studies in using a retrospective point of view, at the end of the semester authors achieved a conceptualization that can be investigated in future studies:

- Segmenting the assignment until each stage has been completed (Table 2, Column 1),

- Changing the difficulty level based on reflections from students at each stage,

- Assigning roles to students (more roles to one, or more roles to both at the same time).

In the context of the CG2's funicular form assignment, Table 2 attempts to segment the process into stages and then map the operations, outputs, and level of intervention of human and computer in such processes. To investigate the level of intervention, a qualitative method was adopted and each step of the formfinding process was critically evaluated based on tutors' observations during the semester.

This analysis shows that the level of intervention of the human is higher in Steps 1, 2, 3, and 8 while the level of intervention of the computer is higher 


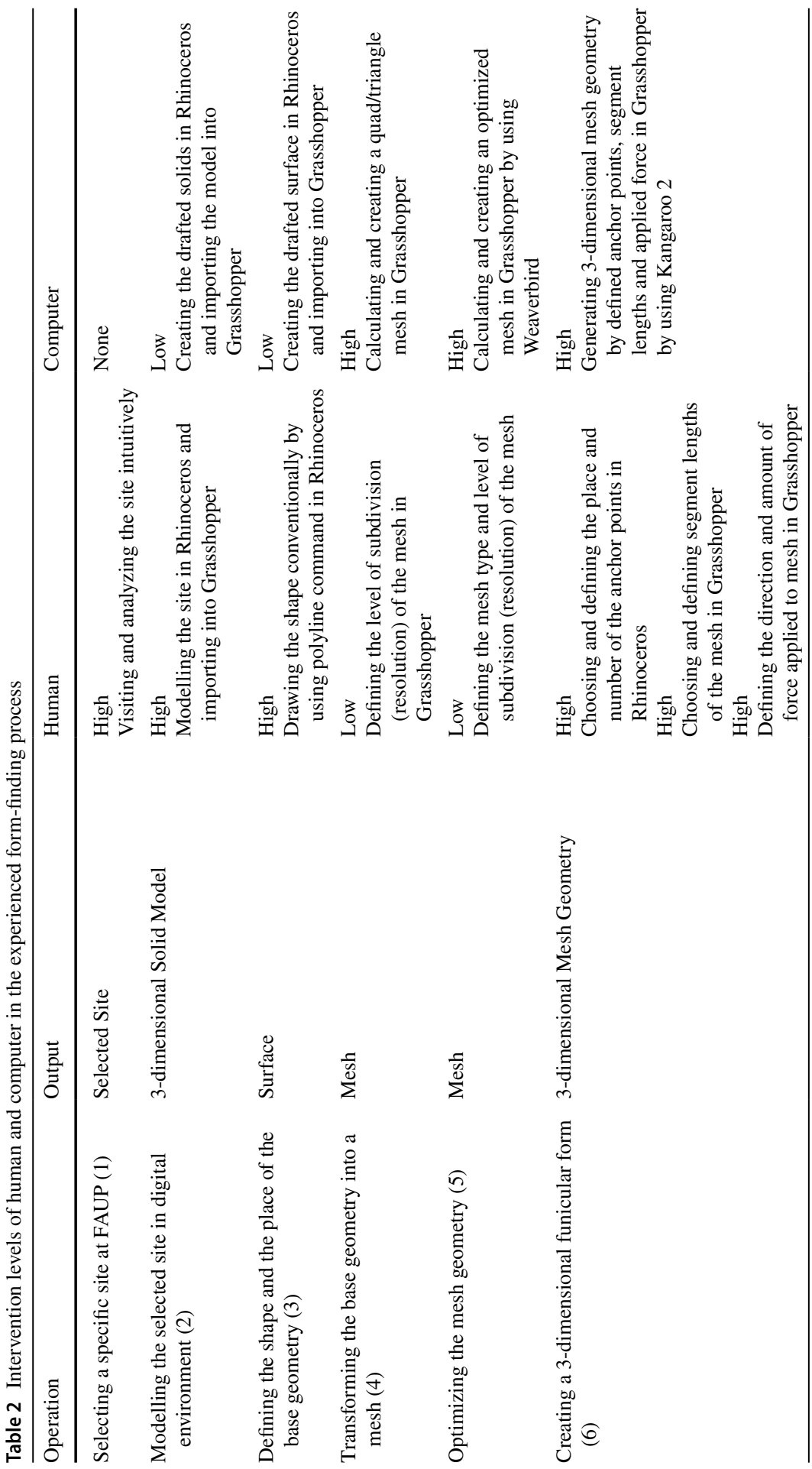




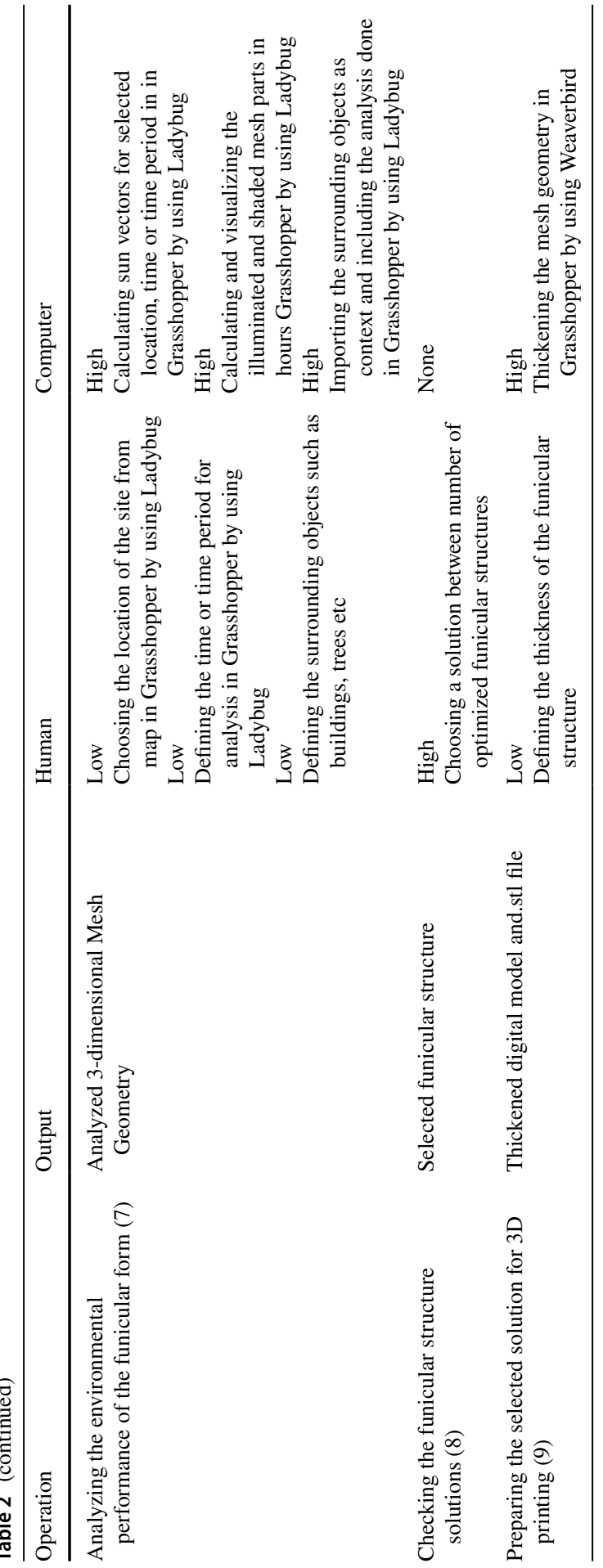


in Steps 4, 5, 7, and 9. In addition, Step 6 suggests that the human and the computer may interfere with the process intensively at the same time. Although the assignment benefits from the human-computer partnership, among possible alternatives the final decision is still made by the human. This also applies to a genetic algorithm approach given that, in the end, the architect can validate the optimal solution or select another one from the population. In this context, in a case where the human factor is neglected, an automatic process without reasoning may produce the same design solutions for the same given data. The fact that architecture is more than achieving an optimal form for a single criterion is reflected in the students' work. Although they follow similar algorithms, their design choices and decisions are different, and they lead the design solutions onto different research paths.

When the form-finding process experienced by the students is examined, it is observed that the human is at the forefront of selecting the site, running and terminating the algorithm, giving inputs that can affect both form and performance, and making choices between alternative solutions. On the other hand, the computer has a central role in generating forms by making calculations according to inputs, making analyzes based on forms and then visualizing them, and translating the forms to make them useful in other physical and digital environments. This teaching experiment also supports the idea that the future of architectural design processes will increasingly integrate intelligent systems and models. Nonetheless, the human factor should not be removed from the equation.

Acknowledgements The authors would like to thank Adrian Krężlik, João Albuquerque, Clara Martins, and Sofia Cunha for sharing their expertise and valuable comments on the assignment. The authors would also like to thank all students in the Constructive Geometry 2 - 2019/20 class for their inspirational and hard work. The research activities of the corresponding author are supported by The Scientific and Technological Research Council of Turkey (Grant no: 1059B191900560).

\section{References}

Adriaenssens, Sigrid, Ruy Marcelo Oliveira Pauletti, Knut Stockhusen, Stefano Gabriele, Paola Magrone, Valerio Varano, Irmgard Lochner-Aldinger. 2015. A project-based approach to learning form finding of structural surfaces. International Journal of Space Structures 30 (3-4): 297-305.

Andrew Borgart, Andrew, Qingpeng Li, and Peter Eigenraam. 2018. Manufacture and loading test of reinforced gypsum shells generated from hanging models - a workshop developed at Delft University of Technology. In: Proceedings of the IASS Symposium 2018 Creativity in Structural Design, pp. 1-8. Boston, MA.

Bodart, Magali, Arnaud Deneyer, André De Herde, and Peter Wouters. 2007. A guide for building daylight scale models. Architectural Science Review 50 (1): 31-36.

Caldas, Luisa. 2008. Generation of energy-efficient architecture solutions applying GENE_ARCH: An evolution-based generative design system. Advanced Engineering Informatics 22 (1): 59-70.

Chilton, John C., and Heinz Isler. 2000. The Engineer's Contribution to Contemporary Architecture: Heinz Isler. London: Thomas Telford Publishing.

Coelho, Rajan Filomeno, Tine Tysmans, and Evy Verwimp. 2014. Form finding \& structural optimization. Structural and Multidisciplinary Optimization 49 (6): 1037-1046.

Dewey, John. 1933. How we Think: A Restatement of the Relation of Reflective Thinking to the Educational Process, Boston, MA: D.C. Health Boston. 
Ekici, Berk, Cemre Cubukcuoglu, Michela Turrin, and I. Sevil Sariyildiz. 2019. Performative computational architecture using swarm and evolutionary optimisation: A review. Building and Environment 147: 356-371.

Henriques, Goncalo Castro and Juarez Moara Franco. 2020. Gridshells: integrating design with structural performance: formal and informal form finding. In: SIGraDi 2020 23th Conference of the Iberoamerican Society of Digital Graphics, pp. 166-173. Medellin, Colombia.

Holzer, Dominik. 2016. Design exploration supported by digital tool ecologies." Automation in Construction 72: 3-8.

Horvat, Miljana, and Maria Wall. 2012. Solar Design of Buildings for Architects: Review of Solar Design Tools. Report T. 41. B. 3. IEA SHC Task 41, Subtask B. Paris, France: International Energy Agency.

Huerta, Santiago. 2003. El cálculo de estructuras en la obra de Gaudí. Ingeniería Civil, 130: 121-133.

Kilian, Axel. 2004. Linking hanging chain models and fabrication, In: Proceedings of the 23rd Annual Conference of the Association for Computer Aided Design in Architecture and the 2004 Conference of the AIA Technology in Architectural Practice Knowledge Community, pp. 110-125. Cambridge (Ontario), Canada.

Kim, Ho-Jeong, Chang-Seok Yang, and Hyeun Jun Moon. 2019. A Study on Multi-Objective Parametric Design Tool for Surround-Type Movable Shading Device. Sustainability 11 (24): 7096.

Meissner, Irene, and Eberhard Möller. 2015. Frei Otto: A Life of Research, Construction and Inspiration. Edition Detail.

Mills, Julie E., and David F. Treagust. 2003. Engineering education-Is problem-based or project-based learning the answer. Australasian Journal of Engineering Education 3 (2): 2-16.

Naboni, Roberto. 2016. Form-finding to fabrication of super-thin anisotropic gridshell. In: Proceedings of XX Congress of the Iberoamerican Society of Digital Graphics SIGraDi 2016. pp. 418-424. Buenos Aires, Argentina.

Oxman, Rivka. 2008. Performance-based design: current practices and research issues. International Journal of Architectural Computing 6 (1): 1-17.

Papert, Seymour. 1993. Mindstorms: Children, Computers and Powerful Ideas, New York, NY: Basic Books.

Peters, Brady, and Terri Peters. 2018. Introduction-Computing the Environment: Design Workflows for the Simulation of Sustainable Architecture. In Computing the Environment: Digital Design Tools for Simulation and Visualisation of Sustainable Architecture, eds. Brady Peters and Terri Peters, $\mathrm{x}-13$. John Wiley \& Sons.

Piaget, Jean. 1972. Psychology and Epistemology: Towards a Theory of Knowledge, London, UK: Penguin.

Piker, Daniel. 2013. Kangaroo: form finding with computational physics. Architectural Design 83 (2): $136-137$.

Rippmann, Matthias, Lorenz Lachauer, and Philippe Block. 2012. Interactive vault design. International Journal of Space Structures 27 (4), 219-230.

Roudsari, Mostapha Sadeghipour, Michelle Pak, and Adrian Smith. 2013. Ladybug: A Parametric Environmental Plugin for Grasshopper to Help Designers Create an Environmentally-Conscious Design. In: Proceedings of the 13th International IBPSA Conference. pp. 3128-3135. Lyon, France.

Shea, Kristina, Robert Aish, and Marina Gourtovaia. 2005. Towards integrated performance-driven generative design tools. Automation in Construction 14 (2): 253-264.

Symeonidou, Ioanna. 2016. Flexible matter: A real-time shape exploration employing analogue and digital form-finding of tensile structures. International Journal of Architectural Computing 14 (4): 322-332.

Turrin, Michela, Peter Von Buelow, and Rudi Stouffs. 2011. Design explorations of performance driven geometry in architectural design using parametric modeling and genetic algorithms. Advanced Engineering Informatics 25 (4): 656-675.

Yazici, Sevil. 2021. The Performance-Based Interlinked Model (PBIM) in Architectural Design: Exchanging Environmental, Structural And Spatial Parameters in the Early Design Stage. METU Journal of the Faculty of Architecture 38 (1): online published. Doi: https://doi.org/10.4305/METU. JFA.2021.1.7

Publisher's Note Springer Nature remains neutral with regard to jurisdictional claims in published maps and institutional affiliations. 
Orkan Zeynel Güzelci received his MSc (2012) degree in Architectural Design Program and PhD (2018) degree in Architectural Design Computing Program at Istanbul Technical University. Between 2010 and 2020, he worked as a full-time faculty member at the Department of Interior Architecture and Environmental Design at Istanbul Kultur University. He is currently a Post-Doctoral Researcher at Digital Fabrication Laboratory (DFL) at the Faculty of Architecture of the University of Porto (FAUP). In his previous works, he focused on the analysis of buildings and built environment with shape grammars, entropy, and genetic algorithms. His current research focuses on advanced applications of digital fabrication in architectural education.

José Pedro Sousa is an Assistant Professor at FAUP where he founded and directs the research group DFL, Digital Fabrication Laboratory. He is a PhD in architecture by the TU Lisbon, Master in Genetic Architectures from the ESARQ-UIC in Barcelona and graduated in Architecture from the FAUP in Porto. He was also a Special Student in Design and Computation at MIT and a Visiting Scholar at the UPENN in the United States. With an interest in exploring the conceptual and material opportunities emerging from the use of digital technologies in architecture, he has developed since 2003 a recognized professional activity merging the realms of practice, research and teaching.

João Pedro Xavier is an architect and full professor at the Faculty of Architecture, University of Porto (FAUP), where he received his degree in 1985 and his Ph.D. in Architecture in 2005. He worked in Álvaro Siza's office from 1986 to 1999. At the same time, he established his own practice as an architect. Xavier is a member of CEAU's research teams - Architecture: Theory, Project, History (ATPH)—andDigital Fabrication Laboratory (DFL). The relationship between architecture and mathematics, especially perspective, is his main research interest. He is the author of the books Perspectiva, perspectiva acelerada e contraperspectiva (Perspective, accelerated perspective and retarded perspective) and Sobre as origens da perspectiva em Portugal (About the origins of perspective in Portugal). In December 2018 he was elected Dean of the FAUP. 